OPEN ACCESS

Edited by:

Ana-Maria Cebolla,

Free University of Brussels, Belgium

Reviewed by:

Remco Polman,

Queensland University of Technology,

Australia

Michael J. Richardson

Macquarie University, Australia

*Correspondence:

Matthew A. Pluss

matthew.a.pluss@student.uts.edu.au

Specialty section:

This article was submitted to

Movement Science and Sport

Psychology,

a section of the journal

Frontiers in Psychology

Received: 20 October 2018

Accepted: 16 January 2019

Published: 30 January 2019

Citation:

Pluss MA, Bennett KJM,

Novak AR, Panchuk D, Coutts AJ and

Fransen J (2019) Esports: The Chess

of the 21st Century.

Front. Psychol. 10:156.

doi: 10.3389/fpsyg.2019.00156

\section{Esports: The Chess of the 21st Century}

\author{
Matthew A. Pluss ${ }^{1 *}$, Kyle J. M. Bennett' ${ }^{1}$, Andrew R. Novak², Derek Panchuk ${ }^{3,4}$, \\ Aaron J. Coutts ${ }^{1}$ and Job Fransen ${ }^{1}$
}

${ }^{1}$ Human Performance Research Centre, Faculty of Health, University of Technology Sydney, Moore Park, NSW, Australia, ${ }^{2}$ High Performance Department, Rugby Australia, Moore Park, NSW, Australia, ${ }^{3}$ Institute of Sport, Exercise and Active Living, Victoria University, Melbourne, VIC, Australia, ${ }^{4}$ Movement Science, Australian Institute of Sport, Bruce, ACT, Australia

For many decades, researchers have explored the true potential of human achievement. The expertise field has come a long way since the early works of de Groot (1965) and Chase and Simon (1973). Since then, this inquiry has expanded into the areas of music, science, technology, sport, academia, and art. Despite the vast amount of research to date, the capability of study methodologies to truly capture the nature of expertise remains questionable. Some considerations include (i) the individual bias in the retrospective recall of developmental activities, (ii) the ability to develop ecologically valid tasks, and (iii) difficulties capturing the influence of confounding factors on expertise. This article proposes that expertise research in electronic sports (esports) presents an opportunity to overcome some of these considerations. Esports involves individuals or teams of players that compete in video game competitions via human-computer interaction. Advantages of applying the expert performance approach in esports include (i) developmental activities are objectively tracked and automatically logged online, (ii) the constraints of representative tasks correspond with the real-world environment of esports performance, and (iii) expertise has emerged without the influence of guided systematic training environments. Therefore, this article argues that esports research provides an ideal opportunity to further advance research on the development and assessment of human expertise.

Keywords: electronic sports, expertise, expert performance, excellence, skilled performance, video games, gaming

\section{INTRODUCTION}

Exploring the boundaries of human performance has fascinated researchers and practitioners in a range of fields and domains (Ericsson and Smith, 1991; Gagné, 2004; Williams and Ericsson, 2005; Gagné, 2013). Decades ago, de Groot (1965) and Chase and Simon (1973) investigated the complex thoughts and processes of expert chess players. Since then, the expert performance approach has been applied to sport (Starkes and Ericsson, 2003; Williams and Ericsson, 2005; Côté et al., 2007), music (Ericsson et al., 1993; Lehmann and Ericsson, 1997; Tang and Giddins, 2016), medicine (Gordon, 1988; Ericsson et al., 2007; Tang and Giddins, 2016), and art (Augustin and Leder, 2006; Mullennix and Robinet, 2018). The aim of the expert performance approach is to identify the key characteristics of an expert and understand how expertise is developed over time (Ericsson and Smith, 1991; Charness and Tuffiash, 2008). According to the expert performance approach, capturing human expertise has three distinct stages (Ericsson and Smith, 1991; Williams and Ericsson, 2005). The first stage involves capturing expert performance of a realworld environment in laboratory-testing (e.g., video/film and virtual reality) and/or field setting 
(e.g., match analysis and simulations). The second stage identifies the underlying mechanisms with process-tracing measures (e.g., visual search behavior, film occlusion, and verbal reports). The third stage is examining how expertise develops through practice history profiling (e.g., questionnaires, interviews, and logbooks) and learning studies (e.g., training interventions). Although the expert performance approach offers a theoretical guide to investigate expertise, considerations about the application of the approach have been raised.

Capturing the skills that define expertise within any domain is a hallmark of the expert performance approach (Ericsson and Smith, 1991; Williams and Ericsson, 2005). This becomes a challenge in domains where a clear and measurable performance outcome is lacking (Williams and Ericsson, 2005). For example, in sport, behavioral constructs (e.g., anticipation and decisionmaking) are difficult to assess within a controlled laboratory setting under standardized conditions (Williams and Ericsson, 2005; Afonso et al., 2012). The difficulty here is developing representative tasks that correspond with the constraints of a real-world environment. This consideration will influence the range of methodologies researchers develop to identify the key characteristics of experts (Ericsson and Smith, 1991; Williams and Ericsson, 2005). Whether distinguishing differences between skill groups or predicting superior performance, the lack of task representativeness has the potential to undermine the validity and reliability of the data. Another consideration is that expertise is largely influenced by external factors, such as talent development programs (e.g., sporting organizations or selective schools) and the guidance of a mentor (e.g., sporting coach or music teacher). Yet, researchers have difficulties capturing the interaction of these confounders towards the development of expertise (Baker et al., 2003). The interrelationship between these factors can complicate our interpretation about the nature of expertise. It has been recommended that future research should embrace new technology that can simulate the constraints of a real-world environment within a controlled laboratory setting, while also collecting accurate and reliable data (Williams and Ericsson, 2005; Boot, 2015; Boot et al., 2017). Given the recent advancements in technology, a new domain known as electronic sports (esports) has emerged. As human-computer interaction mediates esports performance, the virtual nature of esports may not be affected to the same extent by the limitations of previous expertise research. Therefore, this leading article argues that esports provides an excellent opportunity to further advance research on the development and assessment of human expertise.

\section{WHAT IS ESPORTS?}

Esports involve individuals and/or teams of players who compete in video game competitions through human-computer interaction. Participation in esports has increased substantially over the past decade, with an estimated population over 100 million players worldwide. To date, esports research has primarily focused on the factors that influence participation (Griffiths et al., 2003; Braun et al., 2016; Seo, 2016; Seo and Jung, 2016). Although information about player engagement is becoming clear, a scarce amount of research has investigated the factors that underlie expertise in esports. Esports consists of several categories, some of which include multiplayer online battle arena, multiplayer online role-playing, real-time strategy and first-person shooter. A common theme among these categories is that performance is typically carried out in a teambased environment, where a player's avatar is placed in a virtual environment with the goal of eliminating their competitors or achieve an objective (e.g., capture the flag). A player must combine their perceptual-cognitive abilities (e.g., anticipation, visual search behavior, pattern recall, and decision-making) and domain-specific skills (e.g., keyboard and mouse movements) to achieve successful performance. Given esports performance is mediated by human-computer interaction, there are many inherent advantages for expertise research. Firstly, developmental activities are objectively tracked and automatically logged online, which can be used to provide a detailed report on a player's development. Secondly, the constraints of a laboratory setting correspond with a real-world environment of esports. Thirdly, as esports has recently emerged, expertise is yet to be confounded by the influence of guided systematic training environments. The following subsections will discuss in detail the advantages of esports performance research offers to the expertise field.

\section{THE DEVELOPMENTAL ACTIVITIES RELATED TO EXPERTISE}

A prominent area of expertise research is aimed towards understanding how practice can lead to the attainment of expertise (Côté et al., 2007; Ward et al., 2007; Ericsson, 2014). Accurately mapping an individual's practice history can elicit key insights about developmental milestones (Côté and Abernethy, 2012; Ford and Williams, 2012). Qualitative interviews, training study questionnaires and diary reports are commonly used methods to establish a practice history profile (Baker et al., 2003; Memmert et al., 2010; Côté and Abernethy, 2012). Across these methods, participants retrospectively recall their practice activities over their career. Given careers can span many years, careful interpretation is recommended when analyzing the information (Howard, 2011). However, this approach is influenced by an individual's recall bias and memory recall ability. Participants generally overestimate the number of practice hours and time since recent milestones and underestimate the number of practice hours and the time since distant ones, often referred to as the telescoping effect (Kemp, 1988; Howard, 2011). This effect can compromise the validity and reliability of data collected using retrospective recall.

Longitudinal follow-up studies are a valuable alternative compared with retrospective recall. However, longitudinal data collection on human behavior can be expensive, time consuming and requires a large sample size because of poor participant retention (Patel et al., 2003). Despite the clear strengths of the design, this creates difficulties when developing practice history profiles that accurately reflect the trajectory of development. Comparatively, esports software records practice activities online which may provide a suitable medium to further explore the 
relationship between developmental activities and expertise. Both the quantity (e.g., total hours played, matches played, etc.) and quality of performance (e.g., outcome of match, player rating, performance rank, etc.) are automatically logged on online servers that are freely available to the public. The public repositories can establish a practice history profile, which can be updated to follow a player's developmental trajectory throughout their career. Profiling can be performed for all skill levels of esports players, which is useful for tracking across a developmental spectrum rather than just from a dichotomous viewpoint (e.g., elite vs. non-elite) (Swann et al., 2015). Another example is tracking a players and/or teams practice activity throughout a competitive season. Researchers can examine the contribution that different practice activities have on performance. Information gained from this approach can inform coaches and practitioners with developing effective training strategies when preparing for competition. Using this approach reduces the logistical demands on data collection and data analysis, making it a cost effective and time efficient method of analyzing an individual's career trajectory. Another advantage is that the influence of individual recall bias is negated, which improves the validity and reliability of the specific performance outcome measures of interest. While much of the data is publicly available, researchers must ensure that they comply with the legislations, rules and policies of their institution's ethics committee and national regulations. If the data is obtained through a third-party repository, it must comply to the original data licensing structure. Further consideration is required for aspiring players under the age of 18, as their publicly available data will be collected when they are a minor. However, the minimum age requirement to participate in a prized pool tournament is 18 years of age. Lastly, in most cases players have the option to list their online profile as private to prevent access to their personal data. As such, the complex and sensitive nature of this method must be conveyed to the appropriate ethics committee for review. Collectively, esports provides a platform to quantify the developmental activities related to expertise without the limitations associated with long-term follow up studies that rely on retrospective recall.

\section{THE DEVELOPMENT OF ECOLOGICALLY VALID TASKS}

A key area of expertise research is developing tasks that provide accurate and reproducible measurements that can be objectively evaluated in a controlled laboratory setting (Mann et al., 2007; Williams et al., 2011). Many studies in controlled laboratory settings use a form of technology to simulate the constraints of a real-world environment of the domain in question (Williams et al., 2002; Williams and Ericsson, 2005). However, concerns have been raised about whether such tasks indirectly measure a related function or ability rather than the specific and complex mechanisms that mediate expert performance (Williams and Ericsson, 2005; Hadlow et al., 2018). Over time researchers have continued to improve the ecologically validity of taskrepresentative designs to closely resemble the dynamic and everchanging nature of a real-world environment (Williams and Ericsson, 2005; Burgess et al., 2006; Mann et al., 2007). Research studies aimed at quantifying expert performance often trade-off external validity for the internal validity of a task, and vice versa. Evidentially, it remains difficult to develop task representative designs that allow participants to (re)produce the behavior's observed in a real-world environment while maximizing the control that can be exerted over a task.

As human-computer interaction mediates esports performance, it may provide the ideal platform to investigate expertise as task representative designs resemble a real-world environment, without sacrificing internal validity. Traditional task representative designs have used technology (e.g., television screens, computer monitors, and video projector screens) with simulated responses (e.g., pressing a button or key and moving a joystick or mouse) (Hadlow et al., 2018). Despite being highly controllable, the implementation of this method instead of more externally valid tasks will inadvertently alter the perceptionaction coupling of a real-world environment (Kay and Kelso, 2016). However, as esports is mediated by this form of technology for both competition and training, the perception-action coupling experienced during performance can be accurately replicated in a controlled laboratory setting. Researchers can customize in-built settings within the software used in esports to develop highly controlled training interventions without sacrificing task representativeness. An example of this is assessing a range of performance-related characteristics, such as fine-motor coordination, processing ability and decisionmaking. Assessing a range of performance-related characteristics can highlight differences between esports categories where certain characteristics may be more necessary than others. Certain esports (e.g., League of Legends) have regular in-game changes to address game balance issues or provide new content for players. Therefore, the authors propose that researchers should state the current version of the game and provide a reference to the rules at that point of time whenever possible. In rare circumstances that major rule changes occur, these differences should be stated explicitly in-text when discussing esports studies together. Furthermore, an esports player's behavioral response can be measured through the available hardware (e.g., keyboard and mouse responses). Esports with a clear and measurable performance outcome are more suited for performance-related research. Examples where researchers and practitioners can objectively examine a player's performance include the HLTV rating for Counter-Strike: Global Offensive and the Kill/Death/Assist ratio for League of Legends. In terms of learning-related research, esports that allow researchers and practitioners to develop online training scenarios are more suitable. Examples where researchers and practitioners can create their own training interventions within a realistic environment include the authoring tool for Counter-Strike: Global Offensive and the practice tool for League of Legends. Hence, the virtual nature of esports performance can translate a real-world environment within a controlled laboratory setting under standardized conditions. 


\section{THE CONFOUNDING FACTORS THAT INFLUENCE EXPERTISE}

The developmental process of systematically developed expertise reflects the dynamic interaction between natural abilities, intrapersonal skills and environmental factors (Gagné, 2004; Ericsson et al., 2009; Gagné, 2009). Furthermore, catalysts (i.e., intrapersonal, environmental and chance) can either assist or hinder the developmental process (Gagné, 2004). A commonly reported catalyst that confounds the development of expertise is the influence of a guided systematic training environment (Barab and Plucker, 2002; Burgess and Naughton, 2010). Within traditional domains of expertise, individuals who demonstrate an aptitude are identified at an early age and selected to undergo a structured development program. A structured development program is a commonplace in music (i.e., music academies and conservatories), sport (i.e., sports schools and talent development programs), and education (i.e., selective schools for gifted and talented students). These programs provide individuals with high-quality resources (e.g., support staff, specialized coaching, and logistical support) to develop their natural abilities into talents, with the goal of developing excellence (Côté and Abernethy, 2012). As such, the development of expertise is confounded by the practices implemented across the many guided systematic training environments that exist (Baker et al., 2003). However, the effect a guided systematic training environment has on the development of expertise is difficult to quantify. Therefore, investigating expertise in a domain that has been exposed to these confounders to a lesser extent could provide an opportunity into the development of expertise outside of the constraints of guided systematic training environments.

There are many confounders in traditional domains of expertise, such as maturational factors, the role of coach, support from significant others and cultural factors, among others (Baker et al., 2003; Baker and Horton, 2004). The interaction between these factors underlies the likelihood of developing expertise, which is largely determined by the access to a guided systematic training environment (Baker et al., 2003). However, the emergence of esports professionalism has only recently sparked the development of specialized highperformance centers and support staff focused on developing excellence. Therefore, the existing pool of expert esports players have emerged largely without guided systematic training environments. As the professionalism of esports continues

\section{REFERENCES}

Afonso, J., Garganta, J., Mcrobert, A., Williams, A. M., and Mesquita, I. (2012). The perceptual cognitive processes underpinning skilled performance in volleyball: evidence from eye-movements and verbal reports of thinking involving an in situ representative task. J. Sports Sci. Med. 11, 339-345.

Augustin, D., and Leder, H. (2006). Art expertise: a study of concepts and conceptual spaces. Psychol. Sci. 48, 135-156.

Baker, J., and Horton, S. (2004). A review of primary and secondary influences on sport expertise. High Ability Stud. 15, 211-228. doi: 10.1080/13598130420003 14781 to increase, the access to publicly available data of highlevel teams is becoming less accessible. Therefore, the authors encourage esports to follow traditional monitoring approaches by embedding researchers within professional teams to collect data at the highest level of competition. Additionally, the growing population of esports players offers a wealth of information about the interaction of natural abilities and intrapersonal skills. Therefore, esports is a domain that is more likely to reflect an individual's raw abilities and skills as it is yet to be tainted by many of the confounders that complicate our understanding about the development of expertise.

\section{CONCLUSION}

The purpose of this leading article was to provide rationale for why esports is the ideal domain for those with an interest in the assessment and development of human expertise. Three key advantages of applying the expert performance approach in esports were discussed in this article: (i) developmental activities are objectively tracked and automatically logged online, which can be used for a detailed report on a player's developmental trajectory, (ii) the constraints of representative tasks correspond with the real-world environment of esports performance, which translates a real-world environment within a controlled laboratory setting under standardized conditions, and (iii) expertise has emerged without the influence of guided systematic training environments, which presents an opportunity to investigate in a domain yet to be tainted by many of the confounders that complicate our understanding about the development of expertise. As such, esports provides a window for researchers to further improve their understanding about the assessment and development of human expertise in the modern world. Therefore, the authors recommend embracing this emerging area as it may have the answers to many of the future recommendations that the expertise field continues to seek.

\section{AUTHOR CONTRIBUTIONS}

All authors listed have made a substantial, direct and intellectual contribution to the work, and approved it for publication.

Baker, J., Horton, S., Robertson-Wilson, J., and Wall, M. (2003). Nurturing sport expertise: factors influencing the development of elite athlete. J. Sports Sci. Med. 2, 1-9.

Barab, S. A., and Plucker, J. A. (2002). Smart people or smart contexts? Cognition, ability, and talent development in an age of situated approaches to knowing and learning. Educ. Psychol. 37, 165-182. doi: 10.1207/S15326985EP3703_3

Boot, W. R. (2015). Video games as tools to achieve insight into cognitive processes. Front. Psychol. 6:3. doi: 10.3389/fpsyg.2015.00003

Boot, W. R., Sumner, A., Towne, T. J., Rodriguez, P., and Anders Ericsson, K. (2017). Applying aspects of the expert performance approach to better understand the structure of skill and mechanisms of skill acquisition 
in video games. Topics Cognit. Sci. 9, 413-436. doi: 10.1111/tops. 12230

Braun, B., Stopfer, J. M., Müller, K. W., Beutel, M. E., and Egloff, B. (2016). Personality and video gaming: comparing regular gamers, non-gamers, and gaming addicts and differentiating between game genres. Comput. Hum. Behav. 55, 406-412. doi: 10.1016/j.chb.2015. 09.041

Burgess, D. J., and Naughton, G. A. (2010). Talent development in adolescent team sports: a review. Int. J. Sports Physiol. Perform. 5, 103-116. doi: 10.1123/ijspp.5. 1.103

Burgess, P. W., Alderman, N., Forbes, C., Costello, A., Laure, M. C., Dawson, D. R., et al. (2006). The case for the development and use of "ecologically valid" measures of executive function in experimental and clinical neuropsychology. J. Int. Neuropsychol. Soc. 12, 194-209. doi: 10.1017/S1355617706060310

Charness, N., and Tuffiash, M. (2008). The role of expertise research and human factors in capturing, explaining, and producing superior performance. Hum. Factors 50, 427-432. doi: 10.1518/001872008X3 12206

Chase, W. G., and Simon, H. A. (1973). Perception in chess. Cogn. Psychol. 4, 55-81. doi: 10.1016/0010-0285(73)90004-2

Côté, J., and Abernethy, B. (2012). “A developmental approach to sport expertise," in The Oxford Handbook of Sport and Performance Psychology, ed. S. M. Murphy (Oxford: Oxford University Press), 435-447.

Côté, J., Baker, J., and Abernethy, B. (2007). Practice and play in the development of sport expertise. Handb. Sport Psychol. 3, 184-202. doi: 10.1002/9781118270011. ch8

de Groot, A. (1965). Thought and Choice in Chess. The Hague: Mouton.

Ericsson, K. A. (2014). The Road to Excellence: The Acquisition of Expert Performance in the Arts and Sciences, Sports, and Games. Hove: Psychology Press. doi: 10.4324/9781315805948

Ericsson, K. A., Krampe, R. T., and Tesch-Römer, C. (1993). The role of deliberate practice in the acquisition of expert performance. Psychol. Rev. 100, 363-406. doi: 10.1037/0033-295X.100.3.363

Ericsson, K. A., Nandagopal, K., and Roring, R. W. (2009). “An expert performance approach to the study of giftedness," in International Handbook on Giftedness, ed. L. Shavinina (Berlin: Springer), 129-153.

Ericsson, K. A., and Smith, J. (1991). "Prospects and limits of the empirical study of expertise: an introduction," in Toward a General Theory of Expertise: Prospects and Limitse, eds K. A. Ericsson and J. Smith (New York, NY: Cambridge University), 344.

Ericsson, K. A., Whyte, J. IV, and Ward, P. (2007). Expert performance in nursing: reviewing research on expertise in nursing within the framework of the expertperformance approach. Adv. Nurs. Sci. 30, E58-E71. doi: 10.1097/00012272200701000-00014

Ford, P. R., and Williams, A. M. (2012). The developmental activities engaged in by elite youth soccer players who progressed to professional status compared to those who did not. Psychol. Sport Exerc. 13, 349-352. doi: 10.1016/j.psychsport. 2011.09.004

Gagné, F. (2004). Transforming gifts into talents: the DMGT as a developmental theory. High Ability Stud. 15, 119-147. doi: 10.1080/1359813042000314682

Gagné, F. (2009). "Debating giftedness: pronat vs. antinat," in International Handbook on Giftedness, ed. L. Shavinina (Berlin: Springer), 155-204. doi: 10. 1007/978-1-4020-6162-2_7

Gagné, F. (2013). The DMGT: changes within, beneath, and beyond. Talent Dev. Excell. 5, 5-19.

Gordon, D. R. (1988). “Clinical science and clinical expertise: changing boundaries between art and science in medicine," in Biomedicine Examined, eds L. Margaret and D. Gordon (Berlin: Springer), 257-295.

Griffiths, M. D., Davies, M. N., and Chappell, D. (2003). Breaking the stereotype: the case of online gaming. CyberPsychol. Behav. 6, 81-91. doi: 10.1089/ 109493103321167992
Hadlow, S. M., Panchuk, D., Mann, D. L., Portus, M. R., and Abernethy, B. (2018). Modified perceptual training in sport: a new classification framework. J. Sci. Med. Sport 21, 950-958. doi: 10.1016/j.jsams.2018.01.011

Howard, R. W. (2011). Testing the accuracy of the retrospective recall method used in expertise research. Behav. Res. Methods 43, 931-941. doi: 10.3758/s13428011-0120-x

Kay, B., and Kelso, J. (2016). "Information and control: a macroscopic analysis of perception-action coupling," in Perspectives on Perception and Action, ed. H. Heuer (Abingdon: Routledge), 17-46.

Kemp, S. (1988). Dating recent and historical events. Appl. Cogn. Psychol. 2, 181-188. doi: 10.1002/acp.2350020304

Lehmann, A. C., and Ericsson, K. A. (1997). Research on expert performance and deliberate practice: implications for the education of amateur musicians and music students. Psychomusicology 16, 40-58. doi: 10.1037/h0094068

Mann, D. T., Williams, A. M., Ward, P., and Janelle, C. M. (2007). Perceptualcognitive expertise in sport: a meta-analysis. J. Sport Exerc. Psychol. 29, 457-478. doi: 10.1123/jsep.29.4.457

Memmert, D., Baker, J., and Bertsch, C. (2010). Play and practice in the development of sport-specific creativity in team ball sports. High Ability Stud. 21, 3-18. doi: 10.1080/13598139.2010.488083

Mullennix, J. W., and Robinet, J. (2018). Art expertise and the processing of titled abstract art. Perception 47, 359-378. doi: 10.1177/0301006617752314

Patel, M. X., Doku, V., and Tennakoon, L. (2003). Challenges in recruitment of research participants. Adv. Psychiatr. Treatment 9, 229-238. doi: 10.1192/apt.9. 3.229

Seo, Y. (2016). Professionalized consumption and identity transformations in the field of eSports. J. Bus. Res. 69, 264-272. doi: 10.1016/j.jbusres.2015.07.039

Seo, Y., and Jung, S.-U. (2016). Beyond solitary play in computer games: the social practices of eSports. J. Consum. Culture 16, 635-655. doi: 10.1177/ 1469540514553711

Starkes, J. L., and Ericsson, K. A. (2003). Expert Performance in Sports: Advances in Research on Sport Expertise. Champaign, IL: Human Kinetics.

Swann, C., Moran, A., and Piggott, D. (2015). Defining elite athletes: issues in the study of expert performance in sport psychology. Psychol. Sport Exerc. 16, 3-14. doi: 10.1016/j.psychsport.2014.07.004

Tang, J. B., and Giddins, G. (2016). Why and How to Report Surgeons' Levels of Expertise. London: SAGE Publications Sage UK.

Ward, P., Hodges, N. J., Starkes, J. L., and Williams, M. A. (2007). The road to excellence: deliberate practice and the development of expertise. High Ability Stud. 18, 119-153. doi: 10.1080/13598130701709715

Williams, A. M., and Ericsson, K. A. (2005). Perceptual-cognitive expertise in sport: some considerations when applying the expert performance approach. Hum. Mov. Sci. 24, 283-307. doi: 10.1016/j.humov.2005.06.002

Williams, A. M., Ford, P. R., Eccles, D. W., and Ward, P. (2011). Perceptualcognitive expertise in sport and its acquisition: implications for applied cognitive psychology. Appl. Cogn. Psychol. 25, 432-442. doi: 10.1002/acp.1710

Williams, A. M., Ward, P., Knowles, J. M., and Smeeton, N. J. (2002). Anticipation skill in a real-world task: measurement, training, and transfer in tennis. J. Exp. Psychol. 8, 259-270. doi: 10.1037/1076-898X.8.4.259

Conflict of Interest Statement: The authors declare that the research was conducted in the absence of any commercial or financial relationships that could be construed as a potential conflict of interest.

Copyright (C) 2019 Pluss, Bennett, Novak, Panchuk, Coutts and Fransen. This is an open-access article distributed under the terms of the Creative Commons Attribution License (CC BY). The use, distribution or reproduction in other forums is permitted, provided the original author(s) and the copyright owner(s) are credited and that the original publication in this journal is cited, in accordance with accepted academic practice. No use, distribution or reproduction is permitted which does not comply with these terms. 